\title{
Über Hämagglutination bei Tieren.
}

\author{
II. Mitteilung : \\ Heteroagglutination. \\ Von \\ Takeo Shimidzu. \\ (清水武夫) \\ (Aus Prof. Dr. T. Kumagai's medizinischer Klinik \\ der Tohoku-Universität zu Sendai.)
}

\section{Einleitung.}

Bekanntlich ist die wichtigste Grundlage der Immunitätsforschung das Spezifitätsgestez der Antigen-Antikörperreaktion. Nuthal' beobachtete, dass bei der Immunisierung des Kaninchens mit artfremdem Eiweisskörper erzeugtes Präcipitin nicht nur auf das für die Immunisierung benutzte Antigen, sondern, auch auf die Eiweisskörper verwandter Tierspezies wirkte. Durch umfassende Untersuchungen von Stephens $\mathrm{s}^{2)}$ und Arthu $\mathrm{s}^{8)}$ ist es auch festgestellt, dass Antitoxin für Kobragift nicht nur das Kobragift selbst, sondern auch das Toxin anderer Schlangen neutralisieren kann. Bereits im Jahre 1899 erzeugten Ehrlich und Morgenroth ${ }^{4}$ bei der Immunisierung von Kaninchen mit Hammelblutkörperchen Hämolysin, das nicht nur Hammelblutkörperchen, sondern auch Ziegen- und Rinderblutkörperchen auflösen konnte. Auf Grund dieses Ergebnisses haben sie die Behauptung aufgestellt, dass Antigene, die verschiedenen Tierspezies gemeinchaftlich sind, im Tier- und Pflanzenreiche weit verbreitet sein müssten. Thre Vermutung wurde im Jahre 1911 von F or s s m a $n^{5)}$ experimentell als tatsächlich nachgewiesen. Es gelang ihm, durch Immunisierung von Kaninchen mit Meerschweinchen- oder Pferdeorganen streng spezifisches Hämolysin für Hammelblut zu erzeugen, was in der Tat eine überraschende Entdeckung war. Durch weitere Untersuchungen späterer Autoren wurde nacheinander festgestellt, dass auch die Organe der Katze, der Maus, des Hundes, des Huhns, der Schildkröte und die Kiemen einiger Fischarten diese heterospezifische Antigenwirkung haben, während die Organe des Menschen, Kaninchens, Rin- 
des, Schweins, Hammels und der Ratte in dieser Hinsicht ohne Wirkung bleiben.

Die Forssmannsche Entdeckung der heterospezifisehen Antikörperreaktion hat eine neue Bahn für die immunserologischen Forschung eröffinet. Sie spielt in der Biologie und der Medizin eine wirklich grosse theoretische und praktische Rolle. Diese Reaktion ist z. B. die Grundlage für die Theorie sowohl der Wassermannschen als auch der Weil-Felix schen Reaktion. Die Spezifität der natürlichen Antikörper hat zuerst Malk of $f^{())}$in einer Reihe wichtiger Arbeiten untersucht. Er untersuchte die Heteroagglutinationsreaktion normaler Sera von Ziege, Pferd, Menschen, Kaninchen und Taube und fand, dass diese Sera nach der Absorption mit einer Blutsorte noch immer ebenso starke Agglutinationsfähigkeit für andere wie vorher aufwiesen. Aus solchen elektiven Absorptionsversuchen nahm er an, dass Heteroagglutinin nicht aus einheitlichen, sondern aus verschiedenen, aber nur für passende heterogene Blutkörperchen spezifisch agglutinierbaren Stoffen bestehe. Seine Auffassung bestätigten dann auch Land steiner und Sturli, ${ }^{7}$ Ludke $^{8}{ }^{8}$ Rissling ${ }^{9)}$ und Brockmann ${ }^{10)}$. Lüdke hat homologe Versuche auch noch beim Immunserum der Tiere angestellt. Das normale Serum des Kaninchens wirkte auf Blutkörperchen des Hundes und der Maus sehr schwach. Wurde das Kaninchen nun mit Blutkörperchen eines Hundes immunisiert, so agglutinierte sein Immunserum nicht nur Blutkörperchen des Hundes, sondern auch die der Maus sehr stark. Wenn man aber aus diesem Immunserum das Agglutinin für Hundeblutkörperchen absorbierte, so ging auch das Agglutinin für Mausblutkörperchen verloren. Wenn man jedoch aus diesem Kaninchenserum das Agglutinin für Mausblutkörperchen absorbierte, so wurde selbstverständlich das Agglutinin für Mausblutkörperchen entfernt, aber die Reagierfähigkeit gegen Hundeblutkörperchen blieb doch ganz unverändert. Boissevain ${ }^{11)}$ beobachtete, dass das mit Rinderblutkörperchen absorbierte normale Hühnerserum noch das Kaninchenblut agglutinierte, dass dagegen das mit Kaninchenblut absorbierte Hühnerserum nicht mehr gegen Kaninchen- noch auch gegen Rinderblutkörperchen reagierte. Hierauf könnte man folgendes Schema anwenden : für Hühnerserum besitzen Kaninchenblutkörperchen Rezeptor 1 und 2, die Rinderblutkörperchen hingegen nur Rezepter 1 .

Goi ${ }^{12)}$ veröffentlichte während des Ganges meiner Versuche eine Arbeit, nach der Sera des Pferdes, Schweins und Hundes artspezifische Heteroagglutinine und Sera des Menschen, Rindes und der Ziege für Blutkörperchen gewisser Tierspezies spezifische, für die der anderen hingegen gemeinschaftliche Agglutinine besässen. Nach $\mathrm{Yu}^{13)}$ fiel die Heteroagglutination des Pferdeserums bei Blutkörperchen des 
Kaninchens bei Zimmertemperatur negativ und bei niedrigerer Temperatur positiv aus. Kaltes Heteroagglutinin des Pferdeserums wurde mit den genannten Blutkörperchen artspezifisch abgesättigt.

\section{Eigene Versuche.}

\section{Heteroagglutinationsversuch.}

In erster Linie untersuchte ich die Heteroagglutinationsreaktion bei Wärme und Kälte bei den in der I. Mitteilung genannten neun Tierarten. Mit Rücksicht auf verschiedene Resultate mehrerer Untersuchungen, die zur Prüfung der Beobachtung Bordets, dass viele Blutsera normaler Tiere Heteroagglutinine besässen, unternommen wurden, bediente ich mich zur Untersuchung frischen Materials und habe die Sera zuerst inaktiviert, indem ich sie eine halbe Stunde bei $56^{\circ}$ im Wasserbad erhitzte. Durch solche Inaktivierung wurde die Lysinwirkung meistens ausgeschaltet. Zuweilen aber wies das Hundeserum noch Lysinwirkung auf, und Hundeblutkörperchen wurden durch andere inaktivierte Tierseren gelöst. Was das Agglutinationsvermögen der Sera anbelangt, so wurde es dadurch nicht geschädigt. Die ubrigen Verfahren wurden wie bei meiner früheren Arbeit ausgeführt.

Wie man aus Tabelle I ersieht, sind die Resultate sehr verschieden. Das Agglutinationsphänomen des Serums eines Tiers mit Blutkörperchen eines anderen Tiers tritt nicht immer gleichwertig auf, z.B. Kaninchensera agglutinierten Meerschweinchenblutkörperchen einmal intensiv und ein anderes Mal gar nicht. Deshalb ist es wohl nicht richtig, die Existenz dieser Reaktion nach den negativen Resultaten von Untersuchungen, die mit wenig Material ausgeführt wurden, mit Entschiedenheit zu verneinen.

Im allgemeinen besitzen die Blutkörperchen des Kaninchens, Pferdes, Schweins, Huhns und besonders der Kröte stärkere Agglutinabilität als die des Rindes und des Hammels.

Es sei hier erwähnt, dass Krötenserum Blutkörperchen der bereits geprufften Tiere nie agglutiniert und auch Meerschweinchenserum nur sehr schwache Heteroagglutinine besitzt.

Bei sämtlichen Untersuchungen ergibt sich stärkere Agglutination bei Kälte als bei Wärme. Nur das Serum der Kröte zeigte bei Kälte gar keine Fähigkeit, irgendwelche untersuchte Blutsorten zu agglutinieren, während Blutkörperchen der Kröte durch die untersuchten Tiersera, mit Ausnahme des Meerschweinchenserums, agglutiniert wurden. In den meisten,anderen geprüften Fällen gehen die Agglutinierbarkeit des Serums und die Agglutinabilitatt der Blutkörperchen desselben Tierbluts im grossen und ganzen parallel. 
Tabelle I.

Heteroagglutination bei Tieren.

Die Ziffern sind die Zahl der Kombinationen.

\begin{tabular}{|c|c|c|c|c|c|c|c|c|c|c|}
\hline $\begin{array}{c}\begin{array}{c}\text { Blutkör- } \\
\text { perchen } \\
\text { von }\end{array} \\
\text { von }\end{array}$ & 营 & 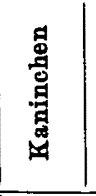 & 总 & 惫 & 点 & 壹 & $\begin{array}{l}\text { 总 } \\
\text { 昌 } \\
\text { 苟 }\end{array}$ & 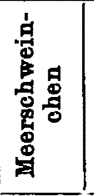 & 韋 & 象 \\
\hline Kaninchen & $\begin{array}{c}37^{\circ} \\
0^{\circ}\end{array}$ & & $\begin{array}{r}+12 \\
-H \\
H \quad 32 \\
-48\end{array} \mid$ & $\left|\begin{array}{ll}H & 62 \\
H & 62\end{array}\right|$ & $\left|\begin{array}{ll} & 122 \\
H & 122\end{array}\right|$ & $\left|\begin{array}{ll}H & 52 \\
H & 18 \\
H & 70\end{array}\right|$ & $\begin{array}{|ll|} \pm & 36 \\
H & 32 \\
H & 68\end{array} \mid$ & $\begin{array}{ll}H & 52 \\
-H & 18 \\
H & 70\end{array} \mid$ & $\left|\begin{array}{ll}H & 62 \\
H & 62\end{array}\right|$ & $\begin{array}{ll}\text { H } & 50 \\
\text { H } & 50\end{array}$ \\
\hline Rind & $\begin{array}{r}37^{\circ} \\
0^{\circ}\end{array}$ & $\left|\begin{array}{ll}H & 142 \\
\text { H } 102\end{array}\right|$ & & $\begin{array}{ll}\text { H } & 56 \\
H & 56\end{array}$ & $\left|\begin{array}{ll}H & 120 \\
H & 120\end{array}\right|$ & $\left|\begin{array}{ll}\text { Ht } & 52 \\
H & 52\end{array}\right|$ & $\left|\begin{array}{ll}+ & 37 \\
\hdashline & 15 \\
H & 32 \\
- & 14\end{array}\right|$ & $\left|\begin{array}{ll}\text { H } & 52 \\
\text { H } & 52\end{array}\right|$ & $\left|\begin{array}{ll}\text { H } & 48 \\
\text { H } & 42\end{array}\right|$ & $\begin{array}{ll}\text { H } & 32 \\
\text { H } & 32\end{array}$ \\
\hline Pferd & $\begin{array}{r}37^{\circ} \\
0^{\circ}\end{array}$ & $\left|\begin{array}{ll}H & 21 \\
- & 39 \\
H & 28\end{array}\right|$ & $\left|\begin{array}{ll}- & 30 \\
\pm & 15 \\
- & 15\end{array}\right|$ & & $\left|\begin{array}{ll}\text { Ht } & 32 \\
\hdashline & 22 \\
\text { H } & 48\end{array}\right|$ & $\begin{array}{rr}+\quad 4 \\
H & 48 \\
H & 48\end{array} \mid$ & $\left|\begin{array}{r}-52 \\
+32 \\
-20\end{array}\right|$ & $\left|\begin{array}{ll}H & 12 \\
-H & 30 \\
H & 28\end{array}\right|$ & $\begin{array}{rr}+ & 8 \\
H & 42 \\
H & 42\end{array} \mid$ & $\mid \begin{array}{ll}\text { H } & 32 \\
\text { H } & 32\end{array}$ \\
\hline Schwein & $\begin{array}{l}37^{\circ} \\
0^{\circ}\end{array}$ & $\left|\begin{array}{ll}\text { Ht } & 68 \\
\text { H } & 68\end{array}\right|$ & $\left|\begin{array}{r}-65 \\
+16 \\
-49\end{array}\right|$ & $\left|\begin{array}{ll}\# & 46 \\
H & 46\end{array}\right|$ & & \begin{tabular}{ll|}
$H$ & 42 \\
$H$ & 42
\end{tabular} & $\left|\begin{array}{rr}H & 4 \\
H & 22 \\
- & 20 \\
- & 6\end{array}\right|$ & $\begin{array}{rr}\text { HI } & 24 \\
H & 4 \\
H & 28\end{array} \mid$ & $\left|\begin{array}{ll}H & 52 \\
H & 48\end{array}\right|$ & $\mid \begin{array}{ll}\text { H } & 36 \\
\text { H } & 36\end{array}$ \\
\hline Hund & $\begin{array}{r}37^{\circ} \\
0^{\circ}\end{array}$ & $\left|\begin{array}{ll}H & 32 \\
H & 32\end{array}\right|$ & $\left|\begin{array}{rr}+ & 3 \\
H & 55 \\
H & 32 \\
- & 28\end{array}\right|$ & $\left|\begin{array}{ll}H & 46 \\
H & 12 \\
- & 22\end{array}\right|$ & $\left|\begin{array}{ll}H & 48 \\
H & 24\end{array}\right|$ & & $\left|\begin{array}{r}-26 \\
+31 \\
-11\end{array}\right|$ & $\left|\begin{array}{ll}H & 28 \\
H & 28\end{array}\right|$ & $\left|\begin{array}{rr}\text { HI } & 36 \\
H & 14 \\
- & 42 \\
- & 8\end{array}\right|$ & $\begin{array}{ll}\text { H } & 38 \\
\text { H } & 38\end{array}$ \\
\hline Hammel & $\begin{array}{r}37^{\circ} \\
0^{\circ}\end{array}$ & $\left|\begin{array}{ll}\text { H } & 32 \\
\text { H } & 32\end{array}\right|$ & $\left|\begin{array}{ll}-35 \\
H & 35\end{array}\right|$ & $\left|\begin{array}{ll}\text { Ht } & 28 \\
\text { H } & 28\end{array}\right|$ & $\left|\begin{array}{ll}H & 25 \\
H & 25\end{array}\right|$ & $\left|\begin{array}{ll}H & 28 \\
H & 28\end{array}\right|$ & & $\left|\begin{array}{ll}\text { H } & 32 \\
\text { H } & 32\end{array}\right|$ & $\left|\begin{array}{ll}\text { H } & 40 \\
H & 40\end{array}\right|$ & $\mid \begin{array}{ll}H & 16 \\
H & 16\end{array}$ \\
\hline $\begin{array}{l}\text { Meerschwein- } \\
\text { chen }\end{array}$ & $\begin{array}{r}37^{\circ} \\
0^{\circ}\end{array}$ & $\begin{array}{ll}- & 28 \\
+ & 28\end{array}$ & $\begin{array}{r}-26 \\
-22\end{array}$ & $\left|\begin{array}{ll}- & 18 \\
H & 20\end{array}\right|$ & $\begin{array}{l}H \quad 24 \\
H \quad 26\end{array}$ & $\left|\begin{array}{rr}t & 6 \\
\hdashline & 18 \\
t+ & 18 \\
- & 6\end{array}\right|$ & $\begin{array}{r}-28 \\
-28\end{array}$ & & $\left|\begin{array}{rr}+\quad 6 \\
-24 \\
-24\end{array}\right|$ & $\begin{array}{l}-16 \\
-20\end{array}$ \\
\hline Huhn & $\begin{array}{c}37^{\circ} \\
0^{\circ}\end{array}$ & $\left|\begin{array}{ll}\text { H } & 88 \\
\text { H } & 48\end{array}\right|$ & $\left|\begin{array}{rr}+ & 72 \\
& 6 \\
W & 76 \\
- & 4\end{array}\right|$ & $\left|\begin{array}{ll}\text { H } & 80 \\
\text { H } & 80\end{array}\right|$ & $\left|\begin{array}{ll}\text { H } & 88 \\
\text { H } & 72\end{array}\right|$ & $\left|\begin{array}{ll}H & 24 \\
H & 24\end{array}\right|$ & $\left|\begin{array}{rr}H & 28 \\
H & 4 \\
H & 34\end{array}\right|$ & $\left|\begin{array}{ll}H & 34 \\
H & 34\end{array}\right|$ & & $\begin{array}{ll}\# & 16 \\
\# & 16\end{array}$ \\
\hline Kröte & $\begin{array}{r}37^{\circ} \\
0^{\circ}\end{array}$ & $\begin{array}{l}-18 \\
-18\end{array}$ & $\begin{array}{l}-18 \\
-18\end{array}$ & $\begin{array}{l}-12 \\
-12\end{array}$ & $\left|\begin{array}{l}-18 \\
-18\end{array}\right|$ & $\left|\begin{array}{l}-16 \\
-16\end{array}\right|$ & $\left|\begin{array}{l}-12 \\
-12\end{array}\right|$ & $\left|\begin{array}{l}-16 \\
-16\end{array}\right|$ & $\left|\begin{array}{l}-16 \\
-16\end{array}\right|$ & \\
\hline
\end{tabular}




\section{Absorptionsversuch.}

Auf Grund von Absorptionsversuchen mitverschiedenen Tierseren berichtete Brockman $n^{10)}$, dass Säugetiersera artspezifische Normalagglutinin für Säugetierblut, aber nicht fur Vogelblut besitzen. Die Vogelsera enthalten.weder für Säugetier- noch für Vogelblut artspezifische Agglutinine.

Durch ähnliche Versuche bekam aber $\mathrm{Goi}^{12}$ ein anderes Resultat. Nach ihm wirkten die Sera des Pferdes, Schweins und Hundes für sämtliche untersuchte Tierblutsorten spezifisch, während das bei den Seren des Rindes und der Ziege nicht der Fall war. Das Blut des Kaninchens absorbierte aus dem Rinderserum Agglutinin für Schweineblut vollständig, für Pferdeblut aber nur teilweise. Nach Absorption aus diesem Serum mit Pferdeblut wurden die Agglutinine für Kaninchenblut erheblich geschwächt und die fürSchweineblut verschwanden vollständig, während Schweine- und Katzenblut bloss die Agglutinine für die eigenen Blutkörperchen absorbierten.

$\mathrm{Zu}$ meiner Untersuchung standen Rind, Kaninchen, Pferd, Schwein, Hammel, Hund, Meerschweinchen und Huhn zur Verfügung. Nach dem vollständigen Verschwinden des Agglutinins für die zur Absorption benutzten Blutkörperchen wurde der Abguss auf Agglutination mit verschiedenen Blutsorten untersucht.

Technik. Die Spezifităt der Agglutinationsfähigkeit normaler Tiersera wurde folgendermassen bestimmt. In $4 \mathrm{ccm}$ frisches inaktiviertes Tierserum wurde $2 \mathrm{ccm}$ Blutkörperchenbrei, der vorher zentrifugiert und mit physiologischer Kochsalzlösung gewaschen worden, getan. Mit diesem Material wurden zuerst zwei Versuchsreihen hergestellt, von denen die eine bei $37^{\circ}$ und die andere bei $0^{\circ}$ geprüft war. Das Serumerythrozytengemisch wurde eine Stunde im Brutschrank bzw. Eiskasten aufbewahrt und durch Zentrifugieren ein klarer Abguss gewonnen. Beim Zentrifugieren wurde das Röhrchen mit dem bei Wärme zu prüfenden Gemisch in einen mit warmem Wasser gefüllten Behälter und das bei Kälte zu prüfende Röhrchen in einen mit zerkleinerten Eisstückchen versehenen gebracht, um dadurch die Reaktionstemperatur immer konstant zu halten. Das Verfahren wurde wiederholt, solange der Abguss die zur Absorption benutzten Blutkörperchen agglutinierte.

In der dritten Versuchsreihe stellte ich den Dissoziationsversuch an, d.h. liess Kälteheteroagglutinin rein in Kochsalzlosung getrennt übergehen. Zu diesem Zwecke wurde der bei Kälte agglutinierende Haufen mit kalter physiologischer Kochsalzlösung im genannten kalten Glasröhrchen dreimal gewaschen und dann mit $2 \mathrm{ccm}$ physiologischer Kochsalzlosung vermischt. Nach einer Stunde im Brutschrank wurde dieses Gemisch zentrifugiert, um den klaren Abguss, in den das Kälteagglutinin übergegangen ist, zu bekommen. Diese 3 Teile, d.h. das bei Wärme und das bei Kalte vorbehandelte Serum und diese dissoziierte Lösung, wurden mit Blutkőrperchen anderer Tierspezies geprüft. Zur Prüfung auf Agglutinabilität wurde 1 Tropfen $(0,05 \mathrm{ccm}) 2$ prozentiger Erythrozytenaufschwemmung in 0,2 ccm Abguss getan. Nach zwei Stunden 
wurde das Resultat beobachtet. Geringe Verminderung der Reaktion gegenuber der vor der Absorption, wie etwa von $H$ auf + , von + auf \pm , wurde nicht berücksichtigt, da solch geringe Unterschiede durch Verdünnung des Serums beim Absorptionsverfahren hervorgerufèn sein könnten.

\section{Versuche mit Kaninchenserum.}

Bei diesem Versuche wurden 15 Kaninchenseren mit Blutkörperchen von 2 Pferden, 4 Schweinen, 4 Hammeln, 3 Hunden und 4 Huhnern absorbiert. Kaninchenserum beeinflusst die Blutkörperchen des Pferdes, Schweins und Hundes artspezifisch, d.h. wenn das Kaninchenserum mit Pferdeblutkörperchen vorbehandelt wurde, so hatte der $\mathrm{Ab}$ guss sein Agglutinationsvermögen für Pferdeblutkbrrperchen verloren, agglutinierte jedoch noch ungeschwächt andere Blutkörperchen. Das Kälteheteroagglutinin war bei der Untersuchung der genannten Kombinationen auch artspezifisch, was die Beobachtung von $\mathrm{Yu},{ }^{13)}$ dass Pferdeserum differenten Blutkörperchen gegenuber bei niedrigerer Temperatur spezifisches Agglutinin besitzt, neu bestätigt. Die Untersuchungen mit Hammel- und Hühnerblutkörperchen erbrachten dagegen ein anderes Resultat. Wurde das Serum mit Hammelblutkörperchen vorbehandelt, so wies der Abguss Agglutinin nicht nur für Hammelblutkörperchen, sondern auch gleichzeitig für Hühnerblutkörperchen deutlich geschwächt auf. Ein Beispiel dieser Versuche ist in Tabelle II gezeigt.

Ausser den oben genannten Ergebnissen kann man aus dem Protokoll noch ersehen, dass der bei Wärme mit Schweineblut vorbehandelte Abguss Blutkörperchen des Schweins bei Kälte noch agglutinieren kann, während bei Kälte vorbehandelter Abguss Blutkörperchen desselben Tieres nicht mehr bei $37^{\circ} \mathrm{zu}$ agglutinieren vermag. Das weist darauf hin, dass bei der Absorption des Kälteagglutinins das Wärmeagglutinin auch mitabsorbiert wird. Der Abguss aber agglutinierte immer noch Blutkörperchen anderer Tierarten, ganz wie vor der Vorbehandlung. Wenn das Kälteheteroagglutinin nur streng spezifische Agglutinierbarkeit hätte, so müsste die dissoziierte Lösung lediglich die betreffenden Blutkörperchen agglutinieren. Sie wirkt jedoch bei $0^{\circ}$ nicht nur auf die betreffenden Blutkörperchen, sondern auch mehr oder weniger auf die anderer Tiere.

Nach diesem Ergebnis können wir in Tierseren das Vorhandensein eines artspezifischen und eines unspezifischen Kälteheteroagglutinins annehmen. Um das unspezifische Agglutinin zu beseitigen, behandelte ich bei $0^{\circ}$ das Serum des Kaninchens mit Blutkörperchen desselben Kaninchens, da das Autoagglutinin seit langem für das unspezifische angesehen wird. Weiter wurde der Abguss mit Schweineblutkörperchen bei $0^{\circ}$ absorbiert. Die Resultate der Heteroaggluti- 


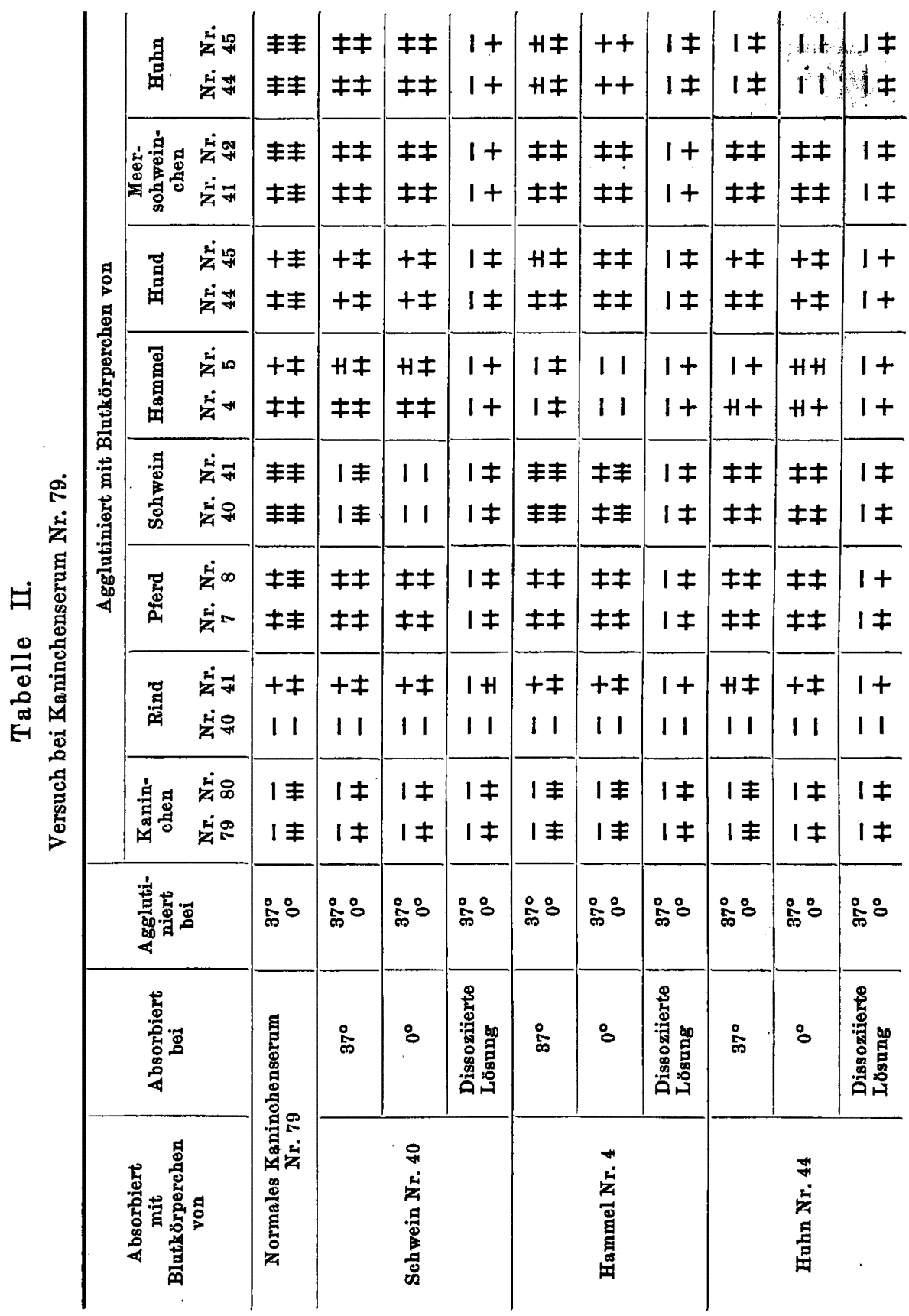


Heteroagglutination

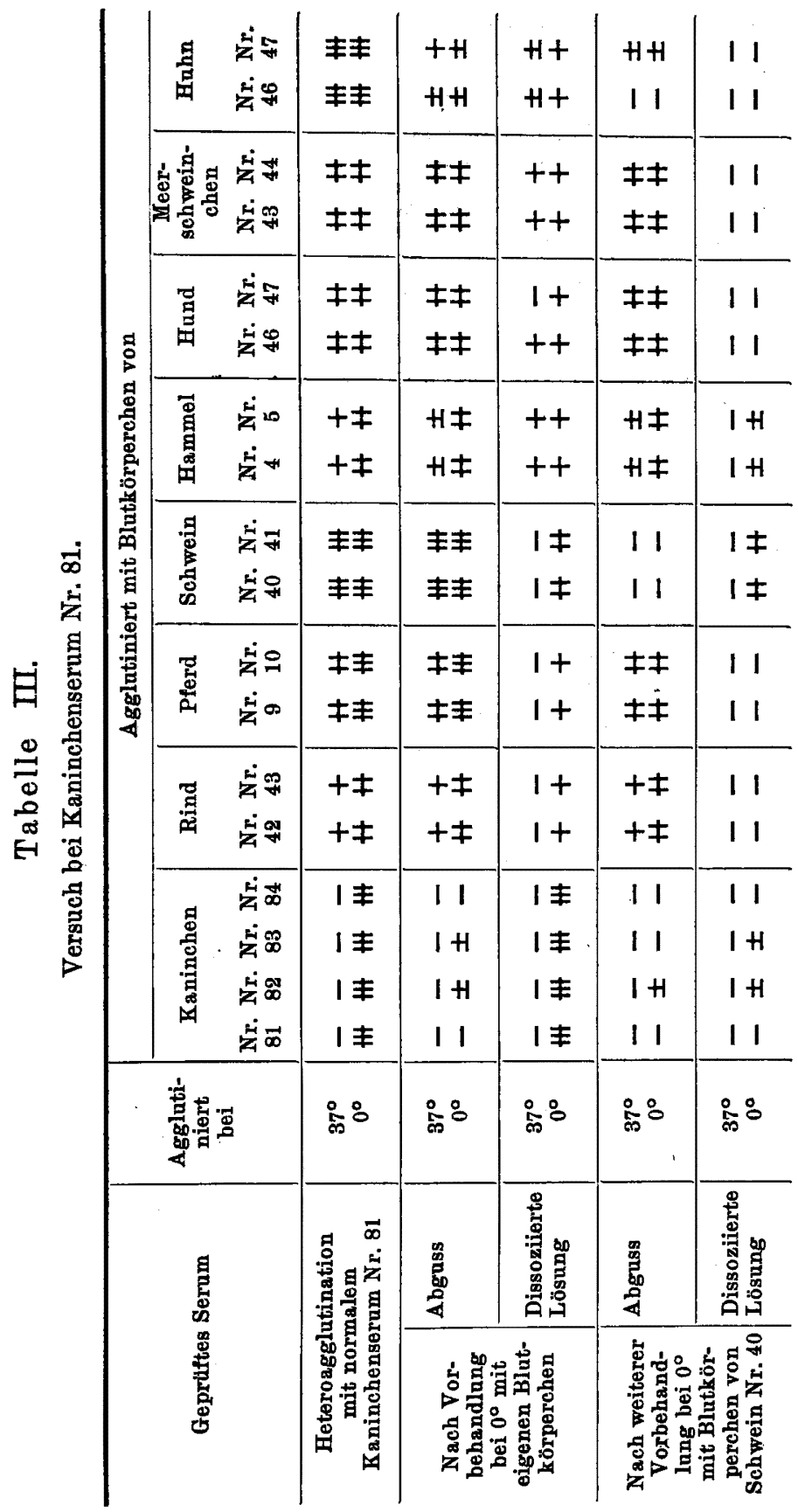


nation des derart behandelten Abgusses sind im Folgenden zusammengestellt.

Wie man aus Tabelle III ersieht, verschwindet aus dem Kaninchenserum die Agglutinationsfähigkeit für Hưhnerblutkörperchen durch den Absorptionsvorgang des Autoagglutinins. Die aus diesen Autoagglutinationshaufen stammende, dissoziierte Lösung agglutinierte bei $0^{\circ}$ Kaninchenblutkörperchen sehr stark und artfremde Blutkörperchen noch deutlich, ja Blutkörperchen des Hammels, des Hundes, des Meerschweinchens und des Huhns wurden sogar bei $37^{\circ}$ mit dieser dissoziierten Lösung agglutiniert. Das Kaninchenserum, dessen unspezifisches Autoagglutinin weggenommen war, wurde weiter mit Schweineblut bei Kälte absorbiert. Das Agguss hatte nur das Agglutinin für Schweineblut verloren, und die aus diesen Agglutinationshaufen stammende, dissoziierte Lösung agglutinierte nur das Schweineblut stark.

Diese Untersuchungen wurden von mir dreimal wiederholt und wiesen immer vollkommen ubereinstimmende Resultate auf, so dass man diese Ergebnisse mit Sicherheit so zussammenfassen kann : Blutkörperchen des Hammels und des Huhns besitzen für Kaninchenserum gemeinschaftliche Rezeptoren, und wenn das Autoagglutinin von dem Kaninchenserum entfernt wird, so wirkt dieses Serum auf Hühnerblut weder bei $37^{\circ}$ noch bei $0^{\circ}$. Wenn man Kaninchenserum mit Blutkörperchen des Rindes, Pferdes, Schweins, Hundes und Meerschweinchens bei $37^{\circ}$ behandelt, so wird sein Agglutinin für die Blutkörperchen jedes einzelnen benutzten Tiers spezifisch absorbiert.

Versuche mit Rinderserum.

Risslin g) $^{9}$ hat Rinderserum mit Pferdeblut und Brockman ${ }^{10)}$ mit Blutkörperchen des Kaninchens, Schweins und Hundes absorbiert. Thre ubereinstimmende Auffassung lautet, dass Rinderserum artspezifische Agglutinine habe. Goi ${ }^{12)}$ absorbierte Rinderserum mit Kaninchenblutkörperchen und beobachtete dabei, dass der Abguss mit Schweineblut gar nicht und der mit Pferdeblut nur sehr schwach agglutinierte. Nach seiner Absorption mit Pferdeblut agglutinierte der Abguss mit Schweineblut auch nicht und der mit Kaninchenblut nur schwach, während von ihm bei der Vorbehandlung mit Schweine- oder Katzenblut nur das Agglutinin für die benutzten Blutkörperchen absorbiert wurde.

Ich behandelte 12 Rindersera mit Blutkörperchen von 3 Kaninchen, 2 Pferden, 6 Schweinen, 4 Hammeln, 3 Hunden, 2 Meerschweinchen und 4 Hühnern. Bei der Absorption bei $37^{\circ}$ waren die Agglutinine für sämtliche untersuchte Blutsorten ganz artspezifisch. Wurde 
das Serum bei $0^{\circ}$ mit Kaninchenblut vorbehandelt, so wurden die Agglutinine für Schweine- und Meerschweinchenblut teilweise absorbiert; wurde das Serum mit Pferdeblut absorbiert, so gingen zum Teil die Agglutinine für Kaninchen und Schwein verloren. Agglutinine für sonstige Tierblutsorten waren auch bei $0^{\circ}$ ganz spezifisch.

Versuche mit Seren von Pferd, Schwein und Hund.

Die Spezifität der Agglutinine des Pferdes, Schweins und Hundes für verschiedene Tierblutsorten ist schon von Landsteiner und Sturli, ${ }^{7}$ Rissling, $\left.{ }^{9}\right)$ Brockman ${ }^{10)}$ und $\mathrm{Goi}^{{ }^{12)}}$ nachgewiesen worden. Nach genauen Untersuchungen stimmen auch meine Ergebnisse mit dieser allgemeinen Auffassung überein, so dass ich sie hier nicht erwähnen will.

\section{Versuche mit Hammelserum.}

Über die Spezifität des Ziegenserums hat Malk of $f^{(6)}$ zuerst eine epochemachende Untersuchung angestellt, wie ich schon in der Einleitung bemerkt habe, und sein Befund, dass das Agglutinin des Ziegenserums für verschiedene Tierarten spezifisch ist, wurde von $R$ is sling wieder bestätigt. Darauf folgte in jüngster Zeit eine Arbeit von Goi, ${ }^{12)}$ in der er einen anderen Befund als den von Malk off und Rissling veröffentlichte. Nach seiner Untersuchung verhielt sich das Ziegenserum so, dass der mit Kaninchenblut vorbehandelte Abguss Hundeblut gar nicht und Pferdeblut nur schwach und auch der mit Katzenblut vorbehandelte Abguss Hundeblut gar nicht und Kaninchenblut nur schwach agglutinierte, während der mit Pferdeblut absorbierte Abguss nur das Agglutinin für arteigene Blutkörperchen verlor, ohne seine Agglutinierbarkeit mit Blutkörperchen von Kaninchen, Hund und Katze zu verändern.

Von mir wurden 10 Hammelsera mit dem Blut von 3 Kaninchen, 2 Pferden, 3 Schweinen, 3 Hunden, 2 Meerschweinchen und $4 \mathrm{H}$ ühnern untersucht. Wenn das Hammelserum mit Blutkörperchen des Kaninchens, Pferdes, Schweins oder Meerschweinchens behandelt wurde, so verschwanden in ihm die Agglutinine spezifisch zur Absorption benutzter Blutsorten, und die Agglutinine für Blutkörperchen anderer Tiere waren im Abguss noch als ungeschwächt nachweisbar. Beim Absorptionsversuch mit Hunde- und Huhnerblut ergab sich aber etwas ganz anderes. Wurde es mit Hunde- bzw. Huhnerblut behandelt, so verlor der Abguss nämlich nicht nur seine Wirksamkeit auf Hundeblut, sondern auch auf Hühnerblutkörperchen.

Es ist somit anzunehmen, dass Hammelserum für Kaninchen, 
Pferd, Schwein und Meerschweinchen spezifische Agglutinine, für Hund und Huhn hingegen die gemeinschaftlichen besitzt.

\section{Versuche mit Huhnerserum.}

Es standen mir 13 Hühnersera und Blutkörperchen von 4 Kaninchen, 3 Rindern, 3 Pferden, 3 Schweinen, 2 Hammeln, 3 Hunden und 2 Meerschweinchen zur Verfügung.

Brockmann $n^{10)}$ fand, dass vom Hühnerserum durch Absorption mit Kaninchenblut die auf Erythrozyten sowohl des Hundes als auch des Schweins und Rindes wirkenden Agglutinine, durch Absorption mit Rinderblut die Agglutinine für Kaninchen-, Schweine- und auch Hundeblut und durch Absorption mit Schweineblut die Agglutinine für Kaninchen-, Rinder- sowie Hammelblut entfernt wurden. Diese auf das Blut dieser Säugetiere wirkenden Agglutinine wurden durch Vogelblut nicht abgesättigt, aber die für das Blut anderer Vogelarten verhielten sich doch anders, z.B. nahm Gänseblut aus dem Hühnerblutserum das auf Entenblut wirkende Agglutinin weg und umgekehrt. Aus seinen Versuchen hat er den Schluss gezogen, dass das Agglutinin des Hühnerserums weder für die untersuchten Säugetierblutarten noch für die untersuchten Vogelblutsorten artspezifisch ist.

Die Ergebnisse meiner Untersuchung beim Hühnerserum sind in folgender Tabelle zussammengestellt.

Wie aus Tabelle IV zu ersehen ist, hat das Kaninchenblut von dem Hühnerserum die auf Blutkörperchen des Hammels, Hundes sowie des Meerschweinchens wirkenden Agglutinine mitabsorbiert. Das Rinderblut hat jedoch die Agglutinine für Hammel- und Meerschweichenblut, das Pferdeblut lediglich die Agglutinine für Hammelblut, das Schweineblut hingegen die Agglutinine für Blutkörperchen des Rindes, Hammels, Hundes und Meerschweinchens deutlich zusammen absorbiert. Das Hammelblut absorbiert von dem Hühnerserum, von dem das Agglutinin für Hammelblut bereits durch anderes Tierblut abgesättigt worden war, das für Meerschweinchenblut geeignete Agglutinin. Die Agglutinationsfähigkeit des Hühnerserums für Blutkörperchen des Rindes, Pferdes, Schweines, Hammels und Hundes wird durch Absorption mit Meerschweinchenblut sehr stark beeinträchtigt.

Danach ist anzunehmen, dass die Rezeptoren des Meerschweinchenbluts für Hühnerserum gemeinschaftliche Elemente mit denen der verschiedenen Tierspezies haben. Unter den gepriften Blutsorten war aber nur das Hundeblut für Hühnerserum artspezifisch.

Ich konnte damit insofern die Brockmannschen Versuche bestätigen, als die Blutkörperchen verschiedener Säugetiere für Hühner- 
Tabelle IV.

Versuch mit Hühnerserum.

\begin{tabular}{|c|c|c|c|c|c|c|c|c|c|c|}
\hline \multirow{2}{*}{ 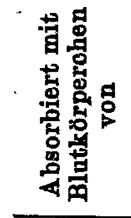 } & \multirow[b]{2}{*}{$\begin{array}{c}\text { Absorbiert } \\
\text { bei }\end{array}$} & \multirow[b]{2}{*}{ 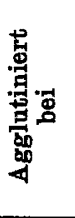 } & \multicolumn{8}{|c|}{ Agglutiniert mit Blutkörperchen von } \\
\hline & & & 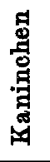 & 荡 & $\begin{array}{l}\text { 营 } \\
\text { 虽 }\end{array}$ & 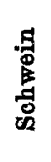 & 焉 & 营 & 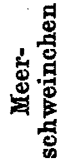 & 韋 \\
\hline \multicolumn{2}{|c|}{$\begin{array}{l}\text { Heteroagglutination mit } \\
\text { normalem Hiahnerserum, } \\
\text { das zum Abborptionsver- } \\
\text { such verwendet wurde }\end{array}$} & $\begin{array}{r}37^{\circ} \\
0^{\circ}\end{array}$ & 無 & $\underset{H}{H}$ & 册 & 州 & $H$ & H & 冊 & $\stackrel{+}{+}$ \\
\hline \multirow{3}{*}{ 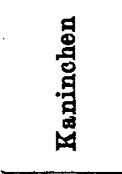 } & $37^{\circ}$ & $\begin{array}{r}37^{\circ} \\
0^{\circ} \\
\end{array}$ & $\bar{H}$ & $H$ & $H$ & $H$ & $\begin{array}{l} \pm \\
\pm\end{array}$ & \pm & $\begin{array}{l} \pm \\
t\end{array}$ & $\begin{array}{l}+ \\
+\end{array}$ \\
\hline & $0^{\circ}$ & $\begin{aligned} 37^{\circ} & \\
0^{\circ} & \end{aligned}$ & $\bar{z}$ & $H$ & $H$ & $H$ & $\bar{z}$ & $\stackrel{t}{+}$ & \pm & + \\
\hline & $\begin{array}{l}\text { Dissozierte } \\
\text { Lösung }\end{array}$ & $\begin{array}{r}37^{\circ} \\
0^{\circ}\end{array}$ & $\bar{H}$ & $\bar{H}$ & $\bar{H}$ & $\bar{H}$ & $\bar{t}$ & $\bar{t}$ & $\bar{t}$ & $\bar{t}$ \\
\hline \multirow{3}{*}{ 苞 } & $\mathbf{3 7}^{\circ}$ & $\begin{array}{r}37^{\circ} \\
0^{\circ}\end{array}$ & 曲 & $\bar{H}$ & $H$ & $H$ & $=$ & H & \pm & + \\
\hline & $0^{\circ}$ & $\begin{array}{r}37^{\circ} \\
0^{\circ} \\
\end{array}$ & 曲 & $=$ & 册 & $H$ & 二 & + & $\overline{-}$ & + \\
\hline & $\begin{array}{l}\text { Dissoziier } \\
\text { Lösung } \\
\end{array}$ & $\begin{array}{r}37^{\circ} \\
0^{\circ} \\
\end{array}$ & $\bar{H}$ & $\bar{H}$ & $\bar{H}$ & $\bar{H}$ & $\overline{+}$ & $\bar{H}$ & $\bar{t}$ & $\overline{+}$ \\
\hline \multirow{3}{*}{$\begin{array}{l}\text { 总 } \\
\text { 中 }\end{array}$} & $37^{\circ}$ & $\begin{array}{r}37^{\circ} \\
0^{\circ}\end{array}$ & $H$ & $H$ & $\bar{H}$ & 曲 & $=$ & $H$ & $H$ & + \\
\hline & $0^{\circ}$ & $\begin{array}{r}37^{\circ} \\
0^{\circ}\end{array}$ & 曲 & $H$ & $=$ & H & = & $H$ & $H$ & $\stackrel{+}{H}$ \\
\hline & $\begin{array}{l}\text { Dissoziler } \\
\text { Lösung }\end{array}$ & $\begin{array}{r}37^{\circ} \\
0^{\circ} \\
\end{array}$ & $\bar{H}$ & $\bar{t}$ & $\bar{H}$ & $\bar{H}$ & $\overline{+}$ & $\bar{H}$ & $\bar{H}$ & $\overline{+}$ \\
\hline \multirow{3}{*}{ 莡 } & $37^{\circ}$ & $\begin{array}{r}37^{\circ} \\
0^{\circ} \\
\end{array}$ & $H$ & $\bar{H}$ & $H$ & $\bar{H}$ & 二 & $H$ & $\stackrel{ \pm}{H}$ & $+t$ \\
\hline & $0^{\circ}$ & $\begin{array}{r}37^{\circ} \\
0^{\circ}\end{array}$ & $H$ & $=$ & $H$ & $\overline{-}$ & - & $\overline{ \pm}$ & $\overline{ \pm}$ & + \\
\hline & \begin{tabular}{|l} 
Dissoziierte \\
Lösung
\end{tabular} & $\begin{array}{r}37^{\circ} \\
0^{\circ} \\
\end{array}$ & $t$ & $\bar{t}$ & \pm & $\bar{H}$ & $\overline{+}$ & $\bar{t}$ & $\bar{H}$ & $\overline{+}$ \\
\hline \multirow{3}{*}{ 惫 } & $37^{\circ}$ & $\begin{aligned} 37^{\circ} & \\
0^{\circ} & \end{aligned}$ & 册 & H & $H$ & 冊 & $\overline{+}$ & $H$ & $\stackrel{+}{H}$ & $\stackrel{+}{H}$ \\
\hline & $0^{\circ}$ & $\begin{array}{r}37^{\circ} \\
0^{\circ}\end{array}$ & 册 & $H$ & $H$ & 册 & $\bar{z}$ & $H$ & + & $\stackrel{+}{H}$ \\
\hline & $\begin{array}{l}\text { Dissozilierte } \\
\text { Lösung }\end{array}$ & $\begin{array}{r}37^{\circ} \\
0^{\circ} \\
\end{array}$ & \pm & $\bar{t}$ & $\bar{H}$ & + & $\bar{H}$ & $\stackrel{+}{\mathrm{H}}$ & $\overline{\text { H }}$ & $\bar{t}$ \\
\hline \multirow{3}{*}{ 鹃 } & $37^{\circ}$ & $\begin{array}{r}37^{\circ} \\
0^{\circ} \\
\end{array}$ & 無 & $H$ & $H$ & $H$ & $H$ & $\bar{H}$ & $H$ & + \\
\hline & $0^{\circ}$ & $\begin{aligned} 377^{\circ} & 0 \\
0^{\circ} & 0\end{aligned}$ & 册 & H & $H$ & H & H & z & H & $\stackrel{+}{H}$ \\
\hline & \begin{tabular}{|l} 
Dissoziierte \\
Lösung \\
\end{tabular} & $\begin{array}{r}37^{\circ} \\
0^{\circ}\end{array}$ & $\bar{H}$ & $\bar{t}$ & $\overline{+}$ & $\bar{H}$ & \pm & $\bar{H}$ & $\bar{t}$ & $\overline{+}$ \\
\hline \multirow{3}{*}{ 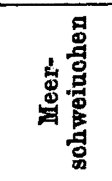 } & $37^{\circ}$ & $\begin{array}{r}37^{\circ} \\
0^{\circ} \\
\end{array}$ & $H$ & + & + & + & $\bar{t}$ & + & $\bar{H}$ & + \\
\hline & $0^{\circ}$ & $\begin{array}{r}37^{\circ} \\
0^{\circ}\end{array}$ & $H$ & $\bar{t}$ & $\overline{ \pm}$ & + & $\overline{ \pm}$ & + & $\overline{-}$ & $\stackrel{+}{H}$ \\
\hline & \begin{tabular}{|l} 
Dissoziierte \\
Lösung
\end{tabular} & $\begin{array}{r}37^{\circ} \\
0^{\circ}\end{array}$ & + & $\bar{t}$ & $\bar{H}$ & $\stackrel{+}{+}$ & $\overline{+}$ & $\stackrel{+}{H}$ & $\bar{H}$ & $\bar{t}$ \\
\hline
\end{tabular}


serum nicht selten gemeinschaftliche Rezeptoren hatten, obgleich sich die von mir erhaltenen einzelnen Resultate nicht vollkommen mit denen Brockmanns deckten.

Im Anchluss an die Beobachtung von Dungern und Hirszfeld ${ }^{14)}$ dass verschiedene Tierblutarten Agglutinin $\beta$ des menschlichen Serum absorbieren, haben mehrere Forscher nacheinander den Zusammenhang des Menschen- und Tierbluts untersucht. Brockman ${ }^{10)}$ beobachtete, dass das Blut des Rindes und des Hundes das menschliche Agglutinin $\beta$ absorbierte und die Sera beider Tiere auf die Struktur A bzw. B des menschlichen Bluts reagierende Agglutinine besassen. Schiff und Adelsberger ${ }^{15)}$ und Dölter ${ }^{16)}$ untersuchten das mit menschlichen Blutkörperchen der Gruppe A immunisierte Kaninchenserum und wiesen in ihm Hammelblutambozeptoren nach. Bialosuknia und Kaczkowski ${ }^{17)}$ stellten fest, dass das menschliche Isoagglutinin $\alpha$ durch Blutkörperchen verschiedener Hammel absorbiert wurde, und dass das Serum des Hammels meistens ausgesprochene Fähigkeit, menschliche Blutkörp rchen der Gruppe A zu agglutinieren, besass. Witebsky, ${ }^{18}$ Kritschewsky und Messik, ${ }^{19}$ Thomsen und Kemp, ${ }^{20)}$ Schermer ${ }^{21)}$ und Lauer ${ }^{20)}$ u.a. haben die Beziehungen der Rezeptoren von Menschen und verschiedenen Tieren untereinander vielfach untersucht. Trotz der grossen Zahl solch ausführlicher Untersuchungen sind nur sehr wenig Absorptionsversuche mit Tierblut unternommen worden. Diese vereinzelt veröffentlichten Untersuchungen kann man jedoch dahin zusammenfassen, dass Säugetierblutsorten mit streng artspezifischen Heteroagglutininen ausgestattet sind. Das Material dieser Untersuchungen waren Sera des Pferdes und des Hundes (Land steiner und Sturli, L üdke) und des Schweins (Rissling).

Auch nach meinen Untersuchungen wiesen diese drei Tiersera ganz artspezifische Heteroagglutinine für sämtliche geprüfte Tierblutsorten auf. Wie schon erwähnt, verhielten sich andere Tiersera nicht so wie diese, so dass man ohne weiteres versteht, dass es sich bei dem Material der hier genannten Autoren zufällig ausschliesslich um Sera handelte, die nur für verschiedene Tierblutsorten artspezifische Heteroagglutinine enthielten. Durch Absorptionsversuche der Tierblutsorten konnte ich das Vorhandensein einer Rezeptorengemeinschaft bei normalem Tierblut feststellen.

\section{Zusammenfassung.}

(1) Die Heteroagglutinierbarkeit und die-agglutinabilität normalen Tierbluts sind je nach der Verschiedenheit der Tierarten mannigfaltig. Unter den gepruften Tieren sind die Blutkörperchen des 
Kaninchens, Schweins, Huhns und der Kröte stark agglutinabel, hingegen die des Rindes und des Hammels sehr schwach, oder sie sind es sogar oft gar nicht. In Bezug auf die Agglutinierbarkeit ist zu bemerken, dass das Serum der Kröte kein Agglutinin für das Blut sämtlicher untersuchter Tiere besitzt. Heteroagglutinin des Meerschweinchenserums ist nur für Schweineblut nachgewiesen worden.

(2) Im allgemeinen geht die Agglutinabilität bei Wärme parallel zu der bei Kälte.

(3) Das Heteroagglutinationsphänomen bei niedrigerer Temperatur wird von zwei verschiedenen Agglutininarten hervorgerufen, von denen die eine spezifisch und die andere unspezifisch ist.

(4) Sera des Pferdes, Schweins und Hundes enthalten für jede der untersuchten Tierblutsorten artspezifische Agglutinine. Sera des Kaninchens, Rindes, Huhns und des Hammels besitzen in ihrem Agglutinin gemeinschaftlicne Elemente für zwei oder noch mehr verschiedene Blutsorten.

(5) Das Hauptergebnis aller aieser Untersuchungen lautet: es gibt eine Rezeptorengemeinschaft für normale Antikörper.

\section{Literaturverzeichnis.}

(1) Nuth a l, Brit. med. journ., 1901, 2, 1141.

(2) Stephens, Journ. of path. a. bact., 1900, 6, 273.

(3) Arthus, Compt. rend. Soc. de Biol., 1914, 77, 268.

(4) Ehrlich u. Morgenroth, Berl. kl. Wochenschr, 1899, 6.

(5) Forssman n, Biochem. Zeitschr., 1911, 87, 78.

(6) Malk off, Deut. med. Wochenschr., 1900, 229.

(7) La ndsteiner u. Sturli, Wien. kl. Wochenschr., 1902, 792.

(8) L ü d ke, Zentralbl. 1. Bakt., 1905, 38, 81.

(9) Rissling, Zentralbl. f. Bakt., 1907, 44, 541.

(10) B rockm a n n, Zeitschr. f. Immunitätsf., 1911, 9, 87.

(11) Boissevain, Compt. rend. Soc. de Biol., 1922, 87, 1255.

(12) Go i, Hokkaido Igaku Zasshi, 1930, 8, 1139.

(13) Y u, Chosen Tgakukai Zasshi, 1927, Nr. 78, 491.

(14) Dungern u. Hirszfeld, Zeitsohr. f. Immunitätsf., 1909, 4, 257, 1910, 6, 284 ; $1911,8,526$.

(15) Schiff u. A dels berger, Zeitschr. f. Immunitätst., 1924, 40, 335.

(16) Dölter, Zeitschr. f. Immunitätsf., 1925, 44, 531.

(17) Bialosuknia u. Kaczkowski, Compt. rend. Soc. de Biol., 1923, 90, 1196.

(18) Witebsky, Zejtschr. f. Immunitätsf., 1927, 49, 1.

(19) Kritschewsky u. Messik, Zeitschr. f. Immunitätsf., 1928, 56, 130.

(20) Thomsen n. Kem p, Zeitschr. f. Immunitätsf., 1930, 67, 257.

(21) Schermer, Zeitschr. f. Immunitätsf., 1930, 68, 437.

(29) L a uer, Zeitschr. f. Immunitktsf., 1930, 68, 434. 